\title{
Correction to: Indicator system for managing science, technology and innovation in universities
}

\author{
Soleidy Rivero Amador ${ }^{1}$ Maidelyn Díaz Pérez² • \\ María José López-Huertas Pérez ${ }^{3}$ - Reinaldo Javier Rodríguez Font ${ }^{4}$
}

Published online: 23 June 2018

(C) Akadémiai Kiadó, Budapest, Hungary 2018

\section{Correction to: Scientometrics \\ https://doi.org/10.1007/s11192-018-2721-y}

This article was originally published online 11 April 2018 copyright The Author(s) with an open access CCC 4.0 international license. However the Society owns copyright for both the original article and this correction. The original article has been corrected.

The original article can be found online at https://doi.org/10.1007/s11192-018-2721-y.

Soleidy Rivero Amador

soly@upr.edu.cu

Maidelyn Díaz Pérez

maidelyn@upr.edu.cu

María José López-Huertas Pérez

mjlopez@ugr.es

Reinaldo Javier Rodríguez Font

rjfont@upr.edu.cu

1 Faculty of Economics and Business, University of Pinar del Río, Martí Street, No. 300. Between November 27 and Gonzalez Alcorta, CP 20100 Pinar del Rio, Cuba

2 Department of Publications and the Information and Knowledge Management Group (proGINTEC), University of Pinar del Río, Martí Street, No. 300. Between November 27 and Gonzalez Alcorta, CP 20100, Pinar del Rio, Cuba

3 Department of Library Science, University of Granada, Campus Universitario de Cartuja. Library of the Colegio Máximo de Cartuja, 18071 Granada, Spain

4 Information and Knowledge Management Group (proGINTEC), University of Pinar del Río, Martí Street, No. 300. Between November 27 and Gonzalez Alcorta, CP 20100, Pinar del Rio, Cuba 